\title{
Arteriosclerosis, Thrombosis, and Vascular Biology
}

\section{American Heart Association

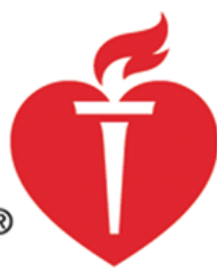 \\ Learn and Live}

Beneficial Effects of Conversion From Cyclosporine to Azathioprine on Fibrinolysis in Renal Transplant Recipients

Marinus A. van den Dorpel, Arie J. Man in't Veld, Marcel Levi, Jan Wouter ten Cate and Willem Weimar

Arterioscler. Thromb. Vasc. Biol. 1999;19;1555-1558

Arteriosclerosis, Thrombosis, and Vascular Biology is published by the American Heart Association. 7272 Greenville Avenue, Dallas, TX 72514

Copyright @ 1999 American Heart Association. All rights reserved. Print ISSN: 1079-5642. Online ISSN: $1524-4636$

The online version of this article, along with updated information and services, is located on the World Wide Web at:

http://atvb.ahajournals.org/cgi/content/full/19/6/1555

Subscriptions: Information about subscribing to Arteriosclerosis, Thrombosis, and Vascular Biology is online at

http://atvb.ahajournals.org/subsriptions/

Permissions: Permissions \& Rights Desk, Lippincott Williams \& Wilkins, 351 West Camden Street, Baltimore, MD 21202-2436. Phone 410-5280-4050. Fax: 410-528-8550. Email:

journalpermissions@1ww.com

Reprints: Information about reprints can be found online at

http://www.lww.com/static/html/reprints.html 


\title{
Beneficial Effects of Conversion From Cyclosporine to Azathioprine on Fibrinolysis in Renal Transplant Recipients
}

\author{
Marinus A. van den Dorpel, Arie J. Man in’t Veld, Marcel Levi, Jan Wouter ten Cate, Willem Weimar
}

\begin{abstract}
Cyclosporin A (CsA) has been implicated as one of the factors contributing to the high cardiovascular morbidity and mortality after renal transplantation. This may be mediated by either a high prevalence of conventional risk factors for atherosclerosis, such as hypertension, hypercholesterolemia, and diabetes mellitus, or by impairment of the fibrinolytic activity evoked by CsA, possibly through interference with prostanoid metabolism. We therefore assessed the impact of conversion of CsA to azathioprine immunosuppressive treatment on parameters of fibrinolytic activity and plasma concentration of the prostanoids prostaglandin $\mathrm{E}_{2}$ and thromboxane $\mathrm{B}_{2}$ in 18 stable renal transplant recipients. During CsA, mean arterial pressure and serum creatinine were significantly higher than during azathioprine $(116 \pm 15 \mathrm{~mm} \mathrm{Hg}$ versus $106 \pm 13 \mathrm{~mm} \mathrm{Hg}, P=0.0003$; and $147 \pm 34 \mu \mathrm{mol} / \mathrm{L}$ versus $127 \pm 35 \mu \mathrm{mol} / \mathrm{L}, P=0.002$; mean $\pm \mathrm{SD}$ ). On conversion, the plasma tissue plasminogen activator activity increased from 1.2 (1.1 to 1.7; median, $95 \% \mathrm{CI})$ to $1.8(1.6$ to 2.0$) \mathrm{IU} / \mathrm{mL}(P=0.011)$, without a significant change of the plasminogen activator antigen concentration. This was associated with a substantial decrease in plasminogen activator inhibitor-1 activity from 10.4 (8.5 to 16.7) to 6.4 (5.6 to 9.2) IU/mL ( $P=0.009$ ). Furthermore, plasma levels of prostaglandin $\mathrm{E}_{2}$ and thromboxane $\mathrm{B}_{2}$ markedly decreased (from 9.7 [7.4 to 12.9 ] to 4.6 [4.3 to 8.1$] \mathrm{pg} / \mathrm{mL}, P=0.0006$; and from 106.1 [91.7 to 214.2] to 70.2 [50.3 to 85.6] pg/mL, $P=0.002$, respectively). During CsA, but not azathioprine, plasma tissue plasminogen activator antigen and plasminogen activator inhibitor- 1 levels correlated significantly with prostaglandin $\mathrm{E}_{2}(r=0.53, P=0.02$; and $r=0.60, P=0.008$, respectively), and thromboxane $\mathrm{B}_{2}(r=0.75, P=0.0001$; and $r=0.77, P=0.0001$, respectively) levels. In conclusion, CsA induced substantial impairment of fibrinolytic activity, which recovered after conversion to azathioprine. The impaired fibrinolysis observed during CsA treatment may be caused by modulation of eicosanoid production or metabolism in vascular endothelial cells and possibly contributes to the high incidence of cardiovascular disease after kidney transplantation. (Arterioscler Thromb Vasc Biol. 1999;19:1555-1558.)
\end{abstract}

Key Words: kidney transplantation $\square$ cyclosporin A $\square$ fibrinolysis $\square$ prostanoids

$I^{n}$ renal transplant recipients the morbidity and mortality caused by atherosclerosis are substantially higher compared with the normal population. ${ }^{1}$ Cardiovascular disease accounts for up to $40 \%$ of deaths after renal transplantation, and there is increasing evidence that patients who are treated with cyclosporin A (CsA) are at high risk. ${ }^{2-4}$ Hypertension and hyperlipidemia are undoubtedly involved; however, disturbances in the fibrinolytic system appear to play an important role in the pathogenesis of atherosclerosis and thrombosis as well.,5 Impaired activity of the fibrinolytic system mostly results from excess plasminogen activator inhibitor-1 (PAI-1), and less commonly from reduced release of tissue or urokinase-type plasminogen activator, and has been associated with the use of the immunosuppressant CsA. ${ }^{7}$ Because of endothelial cell damage and toxicity, CsA has been shown to increase the plasma levels of PAI-1, which results in decreased fibrinolytic activity. ${ }^{8}$ CsA-induced disturbances in prostanoid metabolism may also be implicated in the pathogenesis of the reduced fibrinolytic activity. ${ }^{9}$
We therefore hypothesized that conversion from CsA to azathioprine (AZA) as long-term immunosuppressive therapy would potentially ameliorate fibrinolytic activity. In the first prospective controlled study with paired observations to address this issue, we compared several parameters of the fibrinolytic system in renal transplant patients during CsA and after conversion to AZA treatment to determine the reversibility of the possible harmful effects on the fibrinolytic axis of long-term CsA. Plasma levels of prostaglandin $\mathrm{E}_{2}$ $\left(\mathrm{PGE}_{2}\right)$ and thromboxane $\mathrm{B}_{2}\left(\mathrm{TXB}_{2}\right)$ were determined to assess whether CsA-induced interference with prostanoid metabolism is associated with impaired fibrinolysis, as has been suggested by others. ${ }^{9}$

\[ \text { Methods } \]
Patients
Patients were recruited among renal transplant recipients who had
been enrolled in a prospective randomized clinical trial, which was
designed to evaluate the effects of 2 different immunosuppressive

Received June 17, 1997; revision accepted November 5, 1998.

From the Department of Internal Medicine I (M.A.D., A.J.M.V., W.W.), University Hospital Rotterdam, and the Department of Internal Medicine (M.L., J.W.C.), Academic Medical Center, University of Amsterdam, Amsterdam, The Netherlands.

Correspondence to M.A. van den Dorpel, MD, PhD, Department of Internal Medicine, St. Clara Hospital Rotterdam, Olympiaweg 350,3078 HT Rotterdam, The Netherlands.

(C) 1999 American Heart Association, Inc.

Arterioscler Thromb Vasc Biol. is available at http://www.atvbaha.org 
regimens, ie, prednisone combined with CsA or with AZA, on long-term graft function and incidence of rejection episodes. In this trial all CsA-treated renal transplant recipients, between 18 and 65 years of age, and 6 months or longer after transplantation, were randomly allocated to either continuation of CsA treatment or conversion from CsA- to AZA-based immunosuppression. Patients with diabetes mellitus, proteinuria of $>3 \mathrm{~g} / \mathrm{d}$, acute graft rejection in the previous 3 months, or histological evidence of chronic graft rejection were excluded. The first 18 consecutive patients fulfilling these criteria and willing to give written informed consent were included in the present study, which was approved by the Medical Ethics Committee of the University Hospital Rotterdam.

\section{Study Design}

All patients were examined the first time during CsA, and the second time during AZA. After the first examination, AZA was started at a dose of $2 \mathrm{mg} / \mathrm{kg}$ daily. Two weeks later the CsA dose was reduced to $50 \%$, followed by discontinuation after another 2 weeks. The second examination took place 12 weeks after withdrawal of CsA. Patients used the same dose of prednisone (range, 7.5 to $12.5 \mathrm{mg}$ daily) during both examinations. All antihypertensive medication ( $\beta$-blockers in 13 patients and calcium-channel blockers in 8 patients) was discontinued at least 3 days before both study sessions. All medication influencing the activity of the fibrinolytic system was discontinued at least 3 days before the studies. Patients treated with salicylic acid derivatives were excluded from this study.

\section{Blood Sampling and Assays}

On both study days an intravenous catheter (Venflon, Viggo Spectramed) was inserted in the antecubital vein of the nondominant arm. After 30 minutes of rest in the supine position, venous blood samples were drawn in the appropriate anticoagulant. Platelet-poor plasma was obtained by immediate centrifugation at $1600 \mathrm{~g}$ for 20 minutes at $4^{\circ} \mathrm{C}$. All serum and plasma samples were stored at $-70^{\circ} \mathrm{C}$ until assayed.

Tissue plasminogen activator (tPA) activity was measured by an amidolytic assay. ${ }^{10}$ Briefly, $25 \mu \mathrm{L}$ of plasma was mixed to a final volume of $250 \mu \mathrm{L}$ with $0.1 \mathrm{~mol} / \mathrm{L}$ Tris- $\mathrm{HCl}, \mathrm{pH} 7.5,0.1 \%$ (vol/vol) Tween-80, and $0.3 \mathrm{mmol} / \mathrm{L} \mathrm{S}-2251$ (Chromogenix). The results are expressed as international units per milliliter. PAI-1 activity was measured with an amidolytic assay, ${ }^{11}$ in which the samples were incubated with an excess of tPA $(40 \mathrm{IU} / \mathrm{mL})$ for 10 minutes at room temperature. The residual tPA activity was determined by incubation with $0.13 \mu \mathrm{mol} / \mathrm{L}$ plasminogen (Chromogenix), $0.12 \mathrm{mg} / \mathrm{mL}$ cyanogen bromide-digested fibrinogen fragments (tPA stimulator, Chromogenix), and $0.1 \mathrm{mmol} / \mathrm{L} \mathrm{S}-2251$. The PAI- 1 activity in the sample is inversely proportional to the plasmin generated in the mixture, determined by the conversion of the chromogenic substrate. Results are expressed in international units, where $1 \mathrm{IU}$ is the amount of PAI-1 that inhibits 1 IU tPA. tPA antigen and PAI-1 antigen were assayed with ELISAs ${ }^{12}$ (Asserchrom t-PA, Diagnostica Stago, and PAI-1-ELISA kit, Monozyme, respectively). All results are expressed in nanograms per milliliter.

To assess plasmin generation in vivo, concentrations of plasmin complexed to $\alpha_{2}$-antiplasmin (PAP complexes) were measured by a specific RIA. ${ }^{13}$ Briefly, specific monoclonal antibodies, raised against inactivated and complexed $\alpha_{2}$-antiplasmin, were coupled to Sepharose beads and incubated with plasma. After washing the Sepharose with PBS, bound complexes were subsequently incubated with ${ }^{125}$ I-labeled monoclonal antibodies against plasmin. After another washing step, Sepharose-bound radioactivity was measured. As standards, serial dilutions of plasma in which a maximal amount of PAP complexes was generated by incubation with 2-chain urokinase (Choay) were used. The results are expressed as nanomoles per liter. Our laboratory's normal values of the various components of the fibrinolytic system were determined in age-matched healthy volunteers.

$\mathrm{PGE}_{2}$ and $\mathrm{TXB}_{2}$ were measured with competitive enzyme immunoassays (Cayman Chemical), using a monoclonal antibody against $\mathrm{PGE}_{2}$ and specific polyclonal anti-TXB 2 antibodies, respectively. ${ }^{14}$ Blood 12-hour trough CsA levels were determined with a polyclonal immunoassay (CycloTrac SP, Incstar).
TABLE 1. Patient Characteristics

\begin{tabular}{lcc}
\hline & CsA & AZA \\
\hline Sex, male/female & \multicolumn{2}{c}{$16 / 3$} \\
Age, y & \multicolumn{2}{c}{$41 \pm 23$} \\
Time after transplantation, mo & $24 \pm 5$ & $27 \pm 5$ \\
Body mass index, $\mathrm{kg} / \mathrm{m}^{2}$ & $24.9 \pm 3.5$ & $24.9 \pm 3.3$ \\
Mean arterial pressure, $\mathrm{mm} \mathrm{Hg}$ & $116 \pm 14$ & $109 \pm 12^{*}$ \\
Glomerular filtration rate, $\mathrm{mL} / \mathrm{min}$ & $50 \pm 14$ & $57 \pm 19^{*}$ \\
Prednisone dose, $\mathrm{mg} / \mathrm{d}$ & $9.6 \pm 2.1$ & $9.6 \pm 2.1$ \\
CsA dose, $\mathrm{mg} \cdot \mathrm{kg}^{-1} \cdot \mathrm{d}^{-1}$ & $5.5 \pm 1.7$ & $\ldots$ \\
AZA dose, $\mathrm{mg} \cdot \mathrm{kg}^{-1} \cdot \mathrm{d}^{-1}$ & $\ldots$ & $1.8 \pm 0.4$ \\
\hline$* P<0.05, \mathrm{CsA}$ vs $\mathrm{AZA}$, paired $t$ test. & &
\end{tabular}

\section{Statistics}

All data are presented as median \pm SD, unless indicated otherwise. Paired Student's $t$ test and Wilcoxon's signed rank test were used as appropriate for assessing the statistical significance of the differences between CsA and AZA therapy. The relationships between different parameters were calculated with Pearson's correlation coefficient.

\section{Results}

\section{Clinical Characteristics}

During CsA, mean arterial pressure was significantly higher $(116 \pm 15 \mathrm{~mm} \mathrm{Hg}$ versus $106 \pm 13 \mathrm{~mm} \mathrm{Hg}$; mean $\pm \mathrm{SD}$; $P=0.0003)$, and serum creatinine was significantly higher $(147 \pm 34 \mu \mathrm{mol} / \mathrm{L}$ versus $127 \pm 35 \mu \mathrm{mol} / \mathrm{L}$; mean $\pm \mathrm{SD}$; $P=0.002)$, than during AZA. Body mass index did not change on conversion. The daily dose of prednisone was identical during both treatments (Table 1). No acute rejection episodes occurred between both examination sessions.

\section{Fibrinolysis and Prostanoids}

Conversion from CsA to AZA was followed by an increase in tPA activity from 1.2 (1.1 to 1.7 ) $\mathrm{IU} / \mathrm{mL}$ to 1.8 (1.6 to 2.0$) \mathrm{IU} / \mathrm{mL}$ $(P=0.011$; normal value, $1.7[1.4$ to 2.0$] \mathrm{IU} / \mathrm{mL})$. As shown in Figure 1A, the increase in $\mathrm{PA}$ activity appeared to be caused by a reduction in PAI-1, as reflected by a decrease in plasma levels of PAI-1 antigen (Figure 1D) and associated activity (Figure 1C), and virtually unchanged levels of tPA antigen (Figure 1B). The slight decrease in TPA antigen levels can be readily explained by the fact that this assay also measures tPA-PAI-1 complexes, and will therefore be somewhat affected by decreasing PAI-1 levels. Plasma PAI-1 activity and antigen levels decreased from 10.4 (8.5 to 16.7) to 6.4 (5.6 to 9.2$) \mathrm{IU} / \mathrm{mL}$ ( $P=0.009$; normal, 7.7 [6.1 to 9.3 ] $\mathrm{IU} / \mathrm{mL}$ ), and from 13.4 (9.5 to 18.2$)$ to 8.8 (7.2 to 11.3$) \mathrm{ng} / \mathrm{mL}$ $(P=0.016$; normal, 7.3 [5.9 to 8.7$] \mathrm{ng} / \mathrm{mL})$, respectively. The enhancement of tPA activity resulted in an increase of plasmin formation, as reflected by an increase in PAP complex levels from 3.4 (3.0 to 5.8) to 5.2 (4.1 to 6.4 ) nmol/L ( $P=0.05$; Table 2). Plasma concentrations of both $\mathrm{PGE}_{2}$ and $\mathrm{TXB}_{2}$ were significantly lower during AZA treatment (Table 2).

\section{Correlation Between Prostanoids and Fibrinolysis Parameters}

During CsA but not AZA treatment, we observed strong positive correlations between plasma levels of PAI-1 antigen and $\mathrm{PGE}_{2}$ ( $r=0.60, P=0.008$; Figure 2, top left) and also between PAI-1 antigen and $\mathrm{TXB}_{2}$ ( $r=0.77, P=0.0001$; Figure 2 , top right). The plasma concentration of tPA antigen was positively correlated to 

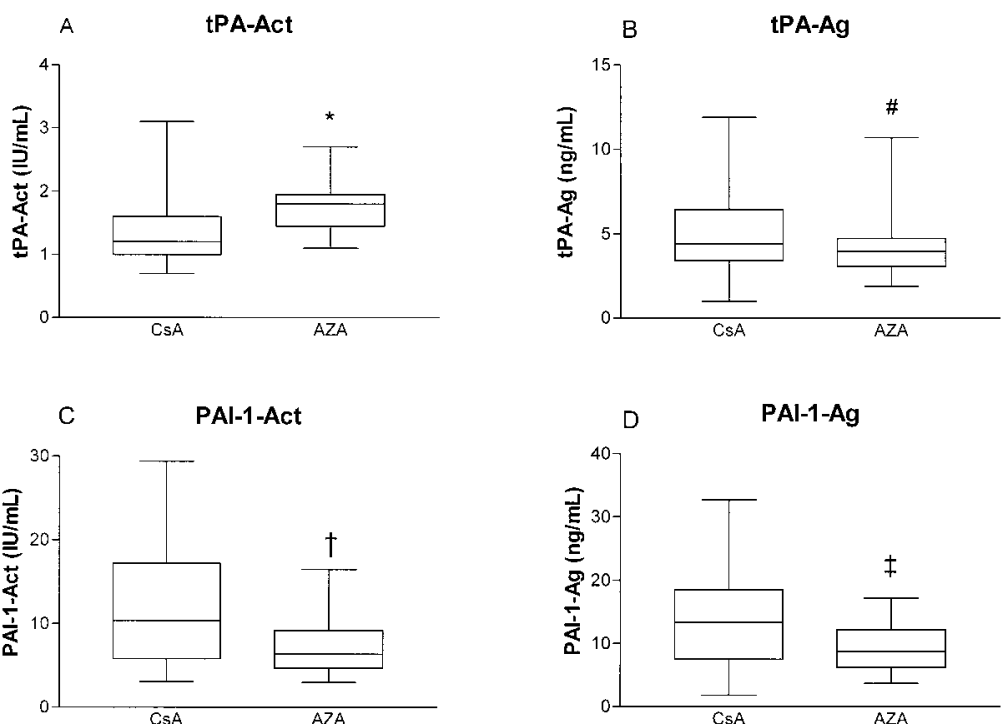

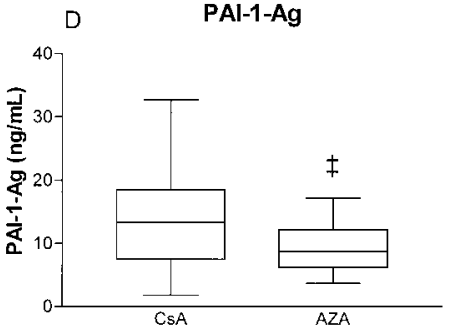

Figure 1. Box whisker plots of plasma tPA activity (tPA-Act; A), tPA antigen (tPA-Ag; B), PAI-1 activity (PAl-1-Act; C), and PAl-1 antigen (PAl-Ag; D) during CsA and AZA treatment. *Indicates $P=0.010$; \#, not significant; †, $P=0.009$; and $\ddagger, P=0.016$; CsA vs AZA by Wilcoxon's signed rank test. plasma $\mathrm{PGE}_{2}(r=0.53, P=0.02)$ and plasma $\mathrm{TXB}_{2} \quad(r=0.75$, $P=0.0001$; data not shown). Interestingly, $\mathrm{TXB}_{2}$ was negatively correlated to tPA activity $(r=-0.70, P=0.001$; Figure 2 , bottom left), which suggests that $\mathrm{TXB}_{2}$-induced elevation of PAI-1 inhibits tPA antigen. This suggestion was supported by the negative correlation between $\mathrm{TXB}_{2}$ and PAP-complex levels $(r=-0.64$, $P=0.004$; Figure 2, bottom right).

\section{Discussion}

The main finding to emerge from our study is that in renal transplant recipients, the activity of the fibrinolytic system increases substantially after conversion from CsA to AZA. The reason for this improvement appears to be a decrease in plasma PAI-1 levels. During CsA, but not AZA, we also found strong correlations between plasma prostanoid levels and several components of the fibrinolytic system.

In a number of studies, impaired fibrinolysis has been associated with the development of acute atherothrombotic events. ${ }^{5,6} \mathrm{We}$ found that PAI-1 activity was significantly higher during CsA, which resulted in a reduction of tPA activity and subsequent plasmin formation as reflected by decreased PAP complexes. This finding is in agreement with data from a cross-sectional study, showing that in a group of CsA-treated renal transplant recipients PAI-1 was higher than in AZA-treated transplant recipients. ${ }^{15}$ The magnitude of the increase of plasma PAI-1 we found during CsA is comparable to the difference in PAI-1 levels between patients with an uneventful course after myocardial infarction and patients who had reinfarction. ${ }^{6}$

The mechanism of this CsA-associated impairment of fibrinolysis is not clear. A defective release of tPA and PAI-1 on

TABLE 2. Plasma Concentrations of PAP Complexes and Prostanoids During CsA and AZA

\begin{tabular}{lccc}
\hline Parameter & CsA & AZA & $P$ Value $^{\star}$ \\
\hline $\mathrm{PAP}, \mathrm{nmol} / \mathrm{L}$ & $3.4(3.0-5.8)$ & $5.2(4.1-6.4)$ & 0.05 \\
$\mathrm{PGE}_{2}, \mathrm{pg} / \mathrm{mL}$ & $9.7(7.4-12.9)$ & $4.6(4.3-8.1)$ & 0.006 \\
$\mathrm{TXB}_{2} \mathrm{pg} / \mathrm{mL}$ & $106.1(91.7-214.2)$ & $70.2(50.3-85.6)$ & 0.002 \\
\hline
\end{tabular}

Data are given as median values $(95 \% \mathrm{Cl})$.

*Calculated by Wilcoxon's signed rank test.
1-deamino-8-D-arginine vasopressin (DDAVP) stimulation was reported in CsA-treated renal transplant recipients, although basal tPA and PAI-1 levels were similar to those of AZA-treated patients. ${ }^{16}$ The impaired DDAVP-induced release of tPA was restored by fish-oil administration, suggesting that a CsAinduced alteration in prostanoid metabolism may be related to the impairment of fibrinolysis.

This hypothesis is supported by our finding that plasma $\mathrm{PGE}_{2}$ and $\mathrm{TXB}_{2}$ decreased markedly after conversion. This is in accordance with other data showing that during CsA systemic and intrarenal prostaglandin synthesis is disturbed. ${ }^{17,18}$ In addition, it has been shown that changes in eicosanoid dynamics may significantly affect vessel wall-related fibrinolytic activity. ${ }^{9}$ The notion that alterations in prostanoid metabolism are involved in the attenuation of fibrinolytic activity during CsA is further corroborated by our finding that plasma $\mathrm{PGE}_{2}$ was closely correlated to plasma tPA activity and PAI-1 antigen and activity levels. In addition, $\mathrm{TXB}_{2}$ was strongly negatively correlated to tPA activity and PAP complexes, and positively correlated to PAI-1 antigen and PAI-1
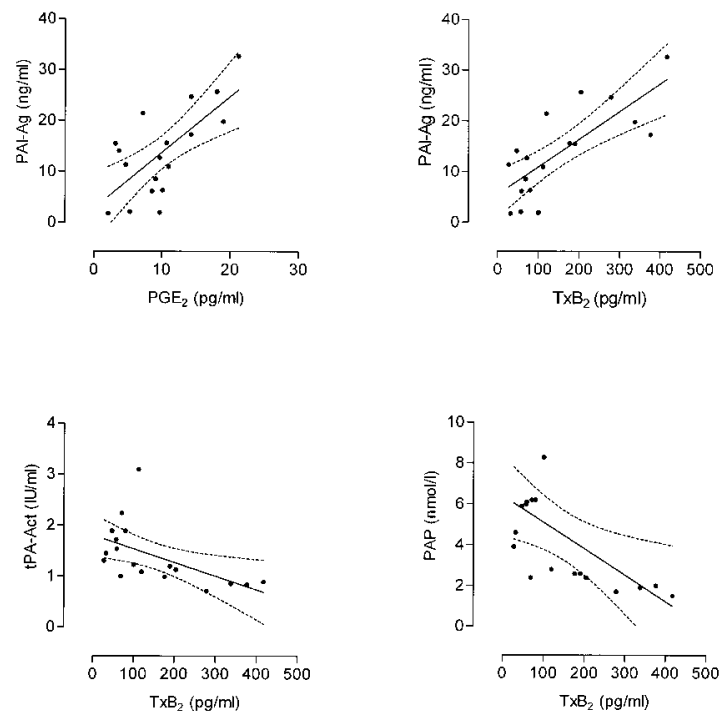

Figure 2. Scatterplots and linear regression lines with $95 \% \mathrm{Cl}$ of relationship between plasma $\mathrm{PGE}_{2}$ or $\mathrm{TXB}_{2}$ and several components of the fibrinolytic cascade during CsA treatment. 
activity. However, during AZA, no correlation between prostanoids and fibrinolytic parameters was present, which may suggest that after conversion the normal regulatory dynamics of fibrinolysis and prostaglandin synthesis was restored.

It is tempting to speculate about alternative explanations for the impairment of fibrinolysis during CsA. In vitro, oxidized LDL is a potent stimulator of the release of PAI-1 by cultured endothelial cells. ${ }^{19}$ Interestingly, we and others recently found that during CsA treatment, LDL is more oxidized, because of increased susceptibility to oxidation both in vivo and in vitro. ${ }^{20,21}$ Therefore, it is conceivable that oxidized LDL may enhance the release of PAI-1 in vivo, resulting in reduced fibrinolytic activity.

The decrease in PAI-1 activity may also be associated with the simultaneous fall in blood pressure after conversion. ${ }^{22}$ In a crosssectional study of healthy young men, the incidence of hypofibrinolysis caused by increased PAI-1 activity was increased in hypertensive subjects. ${ }^{23}$ The association between hypertension and impairment of fibrinolysis may be mediated by a third factor, eg, hyperinsulinemia or insulin resistance. ${ }^{24}$ Other studies have demonstrated significant correlations between hypertriglyceridemia (which was also present during CsA), increased body weight, and hypofibrinolysis caused by increased PAI- $1 .^{25}$

Finally, an alternative mechanism may proceed through the LDL-receptor-related protein $/ \alpha_{2}$-macroglobulin receptor, which is involved in the internalization and intracellular degradation of complexes of plasminogen activator and its inhibitor PAI-1. ${ }^{26} \mathrm{CsA}$ may lead to functional impairment of this receptor, leading to decreased PAI-1 clearance and, consequently, higher PAI-1 plasma levels.

The fact that all patients were examined during CsA first may have influenced our study results. Because of the current practice to use CsA as the initial immunosuppressive drug, randomization to CsA or AZA first was not possible. Therefore, a temporal bias cannot be completely excluded, although the patients had a stable graft function and were on average 24 months after transplantation.

In summary, we found that in renal transplant recipients, conversion from CsA to AZA is accompanied by a substantial enhancement of fibrinolytic activity. Our findings may contribute to the pathogenetic basis for the high incidence of cardiovascular disease after organ transplantation, which has been associated with the long-term use of CsA. ${ }^{2-4}$ Whether the positive effects of long-term treatment with CsA on graft survival are outweighed by the negative effects on cardiovascular morbidity and mortality should be a topic for future studies.

\section{Acknowledgment}

M.L. is a fellow of the Royal Dutch Academy of Arts and Sciences.

\section{References}

1. Raine AEG, Margreiter R, Brunner FP, Ehrich JHH, Geerlings W, Landais P, Loirat C, Mallick NP, Selwood NH, Tufveson G, Valderrona F. Report on management of renal failure in Europe XXII, 1991. Nephrol Dial Transplant. 1992;7(suppl 2):7-35.

2. Murphy BG, Brown JH, McNamee PT. Effect of immunosuppressive drug regime on cardiovascular risk profile following kidney transplantation. Atherosclerosis. 1995;116:241-245.

3. Hollander AAMJ, van Saasse JLCM, Kootte AMM, van Dorp WT, van Bockel HJ, van Es LA, van der Woude FJ. Beneficial effects of conversion from cyclosporin to azathioprine after kidney transplantation. Lancet. 1995;345:610-614.
4. Sutherland F, Burgess E, Klassen J, Buckle S, Paul LC. Post-transplant conversion from cyclosporin to azathioprine: effect on cardiovascular risk profile. Transplant Int. 1993;6:129-132.

5. Thompson SG, Kienast J, Pyke SDM, Haverkate F, van de Loo JCW. Hemostatic factors and the risk of myocardial infarction of sudden death in patients with angina pectoris. $N$ Engl J Med. 1995;332:635-641.

6. Hamsten A, de Faire U, Walldius G, Dahlen G, Szamosi A, Landou C, Blomback M, Wiman B. Plasminogen activator inhibitor in plasma: risk factor for recurrent myocardial infarction. Lancet. 1987;2:3-9.

7. Remuzzi G, Bertani T. Renal vascular and thrombotic effects of cyclosporine. Am J Kidney Dis. 1989;13:261-272.

8. Vanrenterghem Y, Roels L, Lerut T, Gruwez J, Michielsen P, Gresele P, Deckmyn H, Colucci M, Arnout J, Vermylen J. Thromboembolic complications and haemostatic changes in cyclosporin-treated cadaveric kidney allograft recipients. Lancet. 1985;1:999-1002.

9. Winther K, Snorrason K, Knudsen JB, Medgyesi S. The influence of prostacyclin infusion on tissue plasminogen activator. Thromb Res. 1987;46:741-745.

10. Verheijen JH, Mullaart E, Chang GTG, Kluft C, Wijngaards G. A simple, sensitive spectrophotometric assay for extrinsic (tissue-type) plasminogen activator applicable to measurements in plasma. Thromb Haemost. 1982; 48:266-269.

11. Verheijen JH, Chang GTG, Kluft C. Evidence for the occurrence of a fast-acting inhibitor for tissue-type plasminogen activator in human plasma. Thromb Haemost. 1984;51:392-395.

12. Holvoet P, Cleemput H, Collen D. Assay of human tissue-type plasminogen activator (t-PA) with an enzyme-linked immunosorbent assay (ELISA) based on three murine monoclonal antibodies to t-PA. Thromb Haemost. 1985;54:684-687.

13. Levi M, Hack CE, de Boer JP, Brandjes DPM, Buller HR, ten Cate JW Reduction of contact activation related fibrinolytic activity in factor XII deficient patients: further evidence for the role of contact system in fibrinolysis in vivo. J Clin Invest. 1991;88:1155-1160.

14. Pradelles P, Grassi J, MacLouf J. Enzyme immunoassays of eicosanoids using acetylcholine esterase as label: an alternative to radioimmunoassays. Anal Chem. 1985;57:1170-1173.

15. Verpooten GA, Cools FJ, Van der Planken MG, Bedert LC, Claes R, Van Gaal $\mathrm{LF}$, De Broe ME. Elevated plasminogen activator inhibitor levels in cyclosporintreated renal allograft recipients. Nephrol Dial Transplant. 1996;11:347-351.

16. Levi M, Wilmink J, Buller HR, Surachno S, ten Cate JW. Impaired fibrinolysis in cyclosporine-treated renal transplant patients: analysis of the defect and beneficial effect of fish-oil. Transplantation. 1992;54:978-983.

17. Coffmann TM, Carr DR, Harger W, Klotmann PE. Evidence that renal prostaglandin and thromboxane production is stimulated in chronic cyclosporine nephrotoxicity. Transplantation. 1987;43:282-285.

18. Heering P, Strobach H, Schrösr K, Grabensee B. The role of thromboxane and prostacyclin in ciclosporin-induced nephrotoxicity. Nephron. 1992; 61:26-31.

19. Tremoli E, Camera M, Maderna P, Sironi L, Prati L, Colli S, Piovella F, Bernini F, Corsini A, Mussoni L. Increased synthesis of plasminogen activator inhibitor-1 by cultured human endothelial cells exposed to native and modified LDLs. Arterioscler Thromb. 1993;13:338-346.

20. van den Dorpel MA, Ghanem H, Rischen-Vos J, Man in't Veld AJ, Jansen H, Weimar W. Conversion from cyclosporin A to azathioprine treatment improves LDL oxidation in kidney transplant recipients. Kidney Int. 1997;51:1608-1612.

21. Sutherland WHF, Walker RJ, Ball MJ, Stapley SA, Robertson MC Oxidation of low density lipoproteins from patients with renal failure or renal transplants. Kidney Int. 1995;48:227-236.

22. van den Dorpel MA, van den Meiracker AH, Lameris TW, Boomsma F, Levi M, Man in't Veld AJ, Weimar W, Schalekamp MADH. Cyclosporin A impairs the nocturnal blood pressure fall in renal transplant recipients. Hypertension. 1996;28:304-307.

23. Cigolini M, Targher G, Seidell JC, Tonoli M, Schiavon R, Agostino G, De Sandre G. Relationships of blood pressure to fibrinolysis: influence of anthropometry, metabolic profile and behavioural variables. J Hypertens. 1995; 13:659-666.

24. Juhan-Vague I, Alessi MC, Vague P. Increased plasma plasminogen activator inhibitor-1 levels: a possible link between insulin resistance and atherothrombosis. Diabetologia. 1991;34:457-462.

25. Mussoni L, Mannucci L, Sirtori M, Camera M, Maderna P, Sironi L, Tremoli E. Hypertriglyceridemia and regulation of fibrinolytic activity. Arterioscler Thromb. 1992;12:19-27.

26. Orth K, Madison EL, Gething MJ, Sambrook JF, Herz J. Complexes of tissue-type plasminogen activator and its serpin inhibitor plasminogenactivator inhibitor type 1 are internalized by means of the low-density lipoprotein receptor-related protein/alpha 2-macroglobulin receptor. Proc Natl Acad Sci U S A. 1992;89:7422-7426. 